\title{
CLINICAL EXPERIENCE WITH PHENFORMIN TIMED DISINTEGRATION CAPSULES IN INDIAN DIABETICS
}

\author{
M. K. ChHetRI, M.D., M.R.C.P. (Lond) \\ Professor and Head of the Department of Medicine \\ N. D. Chowdhury, M.B., B.S. (Cal) \\ Research Assistant, Department of Medicine
}

\author{
K. PaL, M.B., B.S. (Cal) \\ House Physician, Department of Medicine \\ Bimal De, M.B., B.S. (Cal) \\ Research Assistant, Department of Medicine
}

Institute of Post Graduate Medical Education \& Research, S.S.K.M. Hospital, Calcutta - 20

THE treatment of diabetes mellitus by oral drugs has found general acceptance. Phenformin hydrochloride with a mechanism of action different from that of the sulphonylureas, has been widely used in the Western countries during the last five years and has already acquired a reputation of being an effective drug in the treatment of primary or secondary failures to sulphonylureas and in the smooth control of brittle diabetes (Stowers, 1962; Weller, Donesa and Morton, 1962; Fabrykant and Ashe, 1961; Beaser, 1960; Bloom, Newton and Bateman, 1964). The nature of the response however depends besides other factors on the type of the disease. In India the pattern of diabetes mellitus appears to be slightly different. That the disease in the tropic differs from that in temperate climate has also been stressed earlier (Hugh-Jones, 1955; Cosnett, 1959; DeZoysa, 1951). The classical growth-onset type of the disease is relatively rare. In our clinic amongst 329 patients observed during the last one and a half years only five cases of juvenile diabetes were encountered and none of them was below 10 years of age. The extremely low incidence of juvenile diabetes in the tropics was also stressed by DeZoysa, of Ceylon (1951). However the maturity-onset type of diabetes is quite as common as in Western countries, the only difference being that obesity amongst them is relatively rare, most of them being average weight individuals. Besides these two classical types we have come across diabetes with age of onset between 20 and 40 years differing in some respects from the other groups. Predominantly males, they are usually thin individuals who can remain without insulin for several days with no untoward manifestations. In other words, they are relatively ketoacidosis resistant though they may rarely suffer from this, under extraordinary stressful circumstances. They are also relatively insulin resistant and may require

Paper presented at the World Congress on Diabetes in the Tropics, Bombay, January $20-22,1966$. more than 100 units a day for control. This conforms to the description of "J-type" of Hugh-Jones (1955). Such cases have also been recently described by Tripathy and Kar (1965) from Orissa, India. In our series the incidence of this type has been about $12 \%$. We, however, feel that this does not reflect the true incidence of this type and as its pattern becomes more well known and easily recognisable, the incidence is likely to be more in future. In view of such variations in the pattern of the disease in India, we considered it necessary to assess the efficacy of phenformin hydrochloride timeddisintegration capsules on Indian subjects, since no such study has been made so far.

\section{Materials and Methods}

Ninety consecutive patients attending the Diabetic Clinic of the Hospital entered the trial of which 12 were inpatients. There were 68 males and 22 females. The ages ranged between 16 and 73 years. The duration of diabetes ranged from one month to 24 years. Sixteen patients were obese ( 10 females $), 55$ were of average weight (12 females) and 19 were underweight of which 7 were emaciated. Fifty-one patients were stable maturityonset type (above 40 years), two were growth-onset juvenile type (16 and 14 years). In thirty-four patients the age of onset was between 20 and 40 years; they were ketoacidosis resistant, though some of them passed a little acetone in urine from time to time. Two patients were adult diabetics developing after 20 years but ketoacidosis prone. In one case diabetes had developed following subtotal pancreatectomy.

Sixty-four of the 90 patients had earlier received one or other forms of antidiabetic drugs with variable results. Amongst them were 12 patients with secondary failures, 4 to tolbutamide, 5 to chlorpropamide and 3 to both.

Each patient received 25 calories $/ \mathrm{kg}$. of ideal body weight daily. Correction for sex and obesity was made by deducting 200 calories for the females and 400 calories in the case of obese patients. Additional calories were permitted according to the nature of the activities as follows:-for sedentary workers 400 calories extra, for moderate workers 600 calories extra and for heavy workers $800-1,000$ calories extra. The diet comprised of $200-250 \mathrm{~g}$. of carbohydrate per day, with an allowance of $1 \mathrm{~g}$. of protein $/ \mathrm{kg}$. The remainder of the calories were supplied by fat. 
T A B L E 1

Pre-Therapy Fasting Blood Sugar Distribution

Fasting Blood sugar

Less than $200 \mathrm{mg} . / 100 \mathrm{ml}$.

200 to $250 \mathrm{mg}$.

Over $250 \mathrm{mg}$.

$300 \mathrm{mg}$. and above

No. of cases

32

37

5

12

86

The levels of pretherapy hyperglycaemia in 86 patients are given in Table 1. The remaining four patients who were earlier controlled with sulphonylureas had their blood sugar values within normal limits. The level of fasting hyperglycaemia was below $160 \mathrm{mg} . / 100 \mathrm{ml}$. in only 4 patients and there were two with fasting blood sugar above $400 \mathrm{mg} . / 100 \mathrm{ml}$.

Timed-disintegration DBI capsules (DBI - TD, 50 mg.) were used orally, $100 \mathrm{mg}$. to $200 \mathrm{mg}$. per day in two doses. Changeover from previous antidiabetic drugs to DBI therapy was done after discontinuing the previous therapy for $1-2$ weeks during which period the patients received only dietetic management. The only exception being in the 4 cases mentioned above where the changeover was instituted without any interval.

There were 21 patients in the series (vide Table 5) who had earlier received insulin. In six of them receiving less than 40 units, the changeover was abrupt and no adverse effect was observed. Out of seven other patients receiving more than $\mathbf{4 0}$ units the changeover was abrupt in five and here also no adverse effect was seen. The other eight patients were not taking insulin at the commencement of the trial though they had used it most regularly during some period of their diabetic life.

Patients were asked to report to the clinic after a fortnight for check-up of the fasting and post-prandial blood and urine sugar and for recording the side-effects, if any. In patients who did not achieve satisfactory control within the expected time (usually 3 to 4 weeks) the dose was increased gradually up to the maximum of 4 capsules a day. Whoever failed to respond within 4 to 6 weeks was considered as a primary failure; some of these were treated with combination therapy, the change over being prompt allowing no time for the blood sugar to rise.

Patients who were satisfactorily controlled were allowed to continue the same dose and checked at intervals of 4 to 6 weeks. The total period of observation has since extended over 10 months.

Other laboratory investigations done in some of the inpatients included haemogram, liver function tests e.g. SGOT, SGPT, alkaline phosphatase and serum bilirubin, blood cholesterol; plasma carbon dioxide combining power, serum lactic acid and lactic acid in 24 hours' collection of urine.

\section{Results}

Response to therapy was graded as 'good,' 'fair' and 'poor' according to the following criteria:

\begin{tabular}{|c|c|c|c|}
\hline Response & $\begin{array}{l}\text { Fasting blood } \\
\text { sugar } \\
(\mathrm{mg} . / 100 \mathrm{ml} .)\end{array}$ & Urine sugar & $\begin{array}{l}\text { Post-prandial } \\
\text { blood sugar } \\
\text { (mg./100 ml.) }\end{array}$ \\
\hline Goc & 130 or less & Nil & 180 or less \\
\hline Fair & 130 to 150 & $\begin{array}{l}\text { Nil or } \\
\text { occasional }\end{array}$ & 220 or less \\
\hline
\end{tabular}

Poor above 150
The good and the fair responses were regarded as successful or satisfactory control.

\section{Results of DBI-TD therapy alone}

85 patients received only DBI-TD. The results could be assessed in 66 of them. Of the remaining 19 , the drug had to be discontinued in nine due to side effects permitting no time for proper assessment and 10 patients were dropped from the trial due to their irregular attendance to the clinic. The results of therapy in 66 cases are summarised in Table 2.

\section{T A B L E 2}

RESULTS OF DBI - TD THERAPY IN 66 PATIENTS

$\begin{array}{llc}\text { Result } & \begin{array}{l}\text { No. of } \\ \text { patients }\end{array} & \begin{array}{r}\text { Percentage } \\ \text { of cases }\end{array} \\ \text { Good } & 37 & 56.1 \\ \text { Fair } & 12 & 18.2 \\ \text { Poor } & 8 & 12.1 \\ \text { Primary failure } & 9 & 13.6\end{array}$

A satisfactory response was obtained in $74.3 \%$ of the patients. It was observed that certain factors tended to influence the result of DBI-TD therapy and these factors have been analysed below.

1. Age of onset and type of diabetes: (Table 3). $\triangle$ Amongst the 66 subjects who received only DBI-TD the age of onset was above $\mathbf{4 0}$ years in $\mathbf{3 7}$ individuals. 34 of them $(91.8 \%)$ showed satisfactory control. There were 28 patients with age of onset between 20 and 40 years and one patient below 20 years of age. The success rate in the former group was $53.5 \%$ and none in the latter. Thus age of onset was found to modify the result considerably and statistically this was highly significant $(P<0.001)$. Similar was the pattern of response when the chronological age of patients was considered. The solitary case of post-pancreatectomy diabetes did not respond to DBI-TD and was ultimately controlled with 30 units of insulin.

2. Influence of duration of illness: The incidence of success was highest $(95.2 \%)$ when the duration of the illness was less than one year and the failure rate was very high with the duration of illness more than one year. This was also confirmed statistically $(P<0.05)$. On comparing the success rate in patients with duration of illness less than one year (21 cases) between one to five years (27 cases) and over five years (18 cases) significant difference in the proportion of success $(P<0.05)$ was observed between the first and the last groups.

However closer scrutiny has revealed that this difference was more the reflection of the age of onset rather than of duration per se.

3. Influence of Sex: In females the percentage success was greater $(76.4 \%)$ than in males $(67.5 \%)$. More successes were observed in females with duration less than five years and with age of onset more 
T A B L E 3

Results According to Age of Onset ANd Type of Disease

\begin{tabular}{|c|c|c|c|c|c|}
\hline Age of onset & $\begin{array}{l}\text { Satisfactory } \\
\text { control }\end{array}$ & $\begin{array}{l}\text { Poor } \\
\text { control }\end{array}$ & $\begin{array}{l}\text { Primary } \\
\text { failure }\end{array}$ & Total & $\begin{array}{l}\text { Type of } \\
\text { Diabetes }\end{array}$ \\
\hline $\begin{array}{l}\text { More than } 40 \text { years } \\
\text { Less than } 16 \text { years } \\
20-40 \text { years }\end{array}$ & $\begin{array}{r}34 \\
0 \\
15\end{array}$ & $\begin{array}{l}0 \\
1 \\
7\end{array}$ & $\begin{array}{l}3 \\
0 \\
4\end{array}$ & $\begin{array}{r}37 \\
1 \\
26\end{array}$ & \multirow{3}{*}{$\begin{array}{l}\text { Maturity onset } \\
\text { Growth onset } \\
\text { Ketoacidosis } \\
\text { resistant } \\
\text { Ketoacidosis } \\
\text { prone } \\
\text { Post- } \\
\text { pancreatectomy }\end{array}$} \\
\hline $20-40$ years & 0 & 0 & 1 & 1 & \\
\hline $20-40$ years & 0 & 0 & 1 & 1 & \\
\hline
\end{tabular}

than 40 years (Fig. 1). However statistically this difference was not significant.

4. Relation with bodyweight: There were 11 obese and 12 underweight patients. No difference in the success rate was present between the obese and average weight patients $(72.7 \%$ and $72 \%$ respectively) but the success was comparatively less amongst the underweight patients $(58.3 \%$ ). However, statistical comparison between these groups has revealed no significant difference in the proportion of successes at different probability levels.

5. Relation between pretherapy fasting blood sugar and type of control: In four subjects normoglycaemia achieved by previous sulphonylurea therapy was adequately maintained by the therapy. In the other 62 (Table 4) satisfactory control occurred in $77.9 \%$ when the pretherapy fasting blood sugar was less than $250 \mathrm{mg} / 100 \mathrm{ml}$. and above which the success rate dropped sharply $(53.8 \%)$.

6. Relation with previous therapy: Amongst the 66 patients who could be assessed, 53 had earlier received insulin or sulphonylurea derivatives singly or in combination. The results have been outlined in Table 5.

It is thus seen that the majority of the subjects who were satisfactorily controlled with one of the sulphonylurea derivatives could also be controlled with the DBI-TD. Out of seven subjects with

FIG. 1-The apparent preponderance of success in obese females, females over 40 years of age and with duration less than 5 years is depicted. This was not found to be significant statistically. 
TA B LE 4

Relationship Between Pre-therapy Blood Sugar and Results

\begin{tabular}{lccc}
\hline Types of response & \multicolumn{3}{c}{ Pre-therapy fasting blood sugar } \\
\cline { 2 - 4 } & Below $200 \mathrm{mg}$. & 200 to $250 \mathrm{mg}$. & Above $250 \mathrm{mg} . / 100 \mathrm{ml}$. \\
Good & 18 & 11 & 4 \\
Fair & 3 & 6 & 3 \\
Poor & 4 & 1 & 3 \\
Primary failure & 3 & 3 & 3 \\
\hline
\end{tabular}

T A B L E 5

DBi - TD Result in Previously Treated Patients

\begin{tabular}{llllll} 
& \multicolumn{5}{c}{$D B I-T D$ Results } \\
\cline { 2 - 5 } $\begin{array}{l}\text { Nature and results } \\
\text { of Previous Therapy }\end{array}$ & $\begin{array}{l}\text { Satisfactory } \\
\text { control }\end{array}$ & $\begin{array}{l}\text { Poor } \\
\text { control }\end{array}$ & $\begin{array}{l}\text { Side } \\
\text { effects }\end{array}$ & Primary failure \\
\hline
\end{tabular}

CHLORPROPAMIDE
a) Well controlled
b) Secondary failure
$=6$
$=3$
$=5$
c) Unknown

$\begin{array}{ll}4 & 1 \\ 2 & 0 \\ 2 & 0\end{array}$
$\begin{array}{ll}1 & 1 \\ 0 & 0 \\ 0 & 2\end{array}$
$\begin{array}{ll}1 & 0 \\ 0 & 1 \\ 2 & 1\end{array}$

Tolbutamide

a) Well controlled

b) Secondary failure

c) Poor $\dagger$

d) Primary failure*

e) Unknown

$\begin{array}{ll}=6 & 5 \\ =4 & 2 \\ =1 & 0 \\ =1 & 0 \\ =2 & 1\end{array}$

0
2
0
0
1

1
0
0
0
0

ChLORPRopamide AND

TOLBUTAMIDE

a) Secondary failure

b) Unknown

$$
\begin{aligned}
& =3 \\
& =1
\end{aligned}
$$

0

3
0

0

INSULIN

a) Less than 40 units

b) More than 40 units

c) Unknown

$$
\begin{array}{lll}
=6 & 6 & 0 \\
=7 & 3 & 4 \\
=8 & 6 & 2 \\
\hline
\end{array}
$$

0
0
0

0
1
1

secondary failures to either of the sulphonylurea derivatives, four responded satisfactorily, one displayed primary failure and two reacted poorly. Thus about $57.1 \%$ of the secondary failure cases could be salvaged by DBI-TD. Three subjects who were secondary failure to both chlorpropamide and tolbutamide reacted poorly to DBI-TD. With regard to response to DBI-TD in patients who were earlier treated with insulin it was observed that all cases using less than 40 units showed a satisfactory response. This was not uniformly observed in patients using more than 40 units.

Dose of the drug and time required for control The patients with pretherapy blood sugar below $200 \mathrm{mg}$. $/ 100 \mathrm{ml}$. required only 2 capsules of the drug a day and most of them were controlled by 2-weeks time. Most patients with fasting blood sugar above $250 \mathrm{mg} / 100 \mathrm{ml}$. required four weeks with a dose varying from three to four capsules a day. Patients with fasting blood sugar lying between these two extremes required anything between two and four capsules a day and the time for control also varied from two to five weeks. On closer scrutiny it appears that two capsules a day is the safest initial dose to start with and according to tolerance may have to be increased to three or four capsules a day particularly in patients with higher initial blood sugar (over $200 \mathrm{mg}$./100 ml.) if they do not achieve control even by three weeks time.

\section{Effect of DBI-TD therapy on weight}

Most of the patients lost weight during the initial period of control, only ten having gained weight. The average loss of weight and the average gain was $6.3 \mathrm{lb}$ and $5 \mathrm{lb}$ respectively. Weight loss was mostly observed amongst average and underweight individuals whereas weight gain was 
T A B L E 6

Effect of DBI - TD Therapy on Weight (63 Patients)

\begin{tabular}{lccc}
\hline & $\begin{array}{c}\text { Over weight } \\
(10)\end{array}$ & $\begin{array}{c}\text { Avergae weight } \\
(41)\end{array}$ & $\begin{array}{c}\text { Underweight } \\
(12)\end{array}$ \\
\hline WEIGHT Lost (39): & 3 & 27 & 5 \\
Satisfactory control & 1 & 2 & 1 \\
Poor control & 0 & 0 & 0 \\
Primary failure & & & 0 \\
WEIGHT GAINED (10): & 0 & 2 & 0 \\
Satisfactory control & 0 & 2 & 3 \\
Poor control & 1 & 3 & 2 \\
Primary failure & 4 & 1 & 1 \\
WEIGHT UNCHANGED (14): & 0 & 2 & 0 \\
Satisfactory control & 1 & & \\
Poor control & Primary failure & &
\end{tabular}

T A B L E 7

Side EFFECTS WITH DBI - TD THERAPY

\begin{tabular}{|c|c|c|c|c|c|c|c|c|c|}
\hline $\begin{array}{l}\text { Nausea } \\
\text { Anorexia } \\
\text { Vomiting } \\
\text { Diarrhoea } \\
\text { Giddiness } \\
\text { Weakness }\end{array}$ & $\begin{array}{r}11 \\
9 \\
3 \\
4 \\
3 \\
1\end{array}$ & & \multicolumn{5}{|c|}{$\begin{array}{l}\text { Epigastric discomfort } \\
\text { Dryness of mouth } \\
\text { Burning sensation in rectum and urethra } \\
\text { Sensation of warmth on head } \\
\text { Hypoglycaemia } \\
\text { Palpitation }\end{array}$} & \multirow[t]{3}{*}{$\begin{array}{l}1 \\
1 \\
1 \\
1 \\
1 \\
1\end{array}$} & 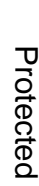 \\
\hline \multirow{2}{*}{\multicolumn{8}{|c|}{$\begin{array}{c}\text { T A B L E } 8 \\
\text { FolLow UP (48 CASES) }\end{array}$}} & & 음 \\
\hline & & & & & & & & & ตे \\
\hline \multicolumn{2}{|c|}{$\begin{array}{l}\text { Duration of follow up in months } \\
\text { No. of patients }\end{array}$} & $\begin{array}{l}4 \\
6\end{array}$ & $\begin{array}{r}5 \\
11\end{array}$ & $\begin{array}{r}6 \\
13\end{array}$ & $\begin{array}{l}7 \\
8\end{array}$ & $\begin{array}{l}8 \\
7\end{array}$ & $\begin{array}{l}9 \\
3\end{array}$ & $\begin{array}{r}10 \\
1\end{array}$ & \\
\hline
\end{tabular}

mostly seen amongst underweight patients (Table 6). Most of these patients who lost some weight during therapy ultimately achieved success; on the other hand most of those who gained weight ended in failure.

\section{Primary Failure}

Nine subjects failed to respond to therapy primarily. Most of these patients were below 40 years of age with duration of illness over one year and all had received other forms of therapy previously. Five of them were sulphonylurea failure (secondary) cases and one had developed the disease following pancreatectomy.

\section{Side Effects}

Most of the side-effects were gastrointestinal. These are listed in Table 7.

Out of 15 patients who developed side effects, in nine these were severe enough to warrant discontinuation of therapy. At the start of therapy many patients developed slight nausea, weakness and anorexia but these never posed a problem as the patients adjusted themselves to these with the continuation of the drug. Some required help of triflupromazine hydrochloride administered twice or thrice daily before the meals to get over their nausea or vomiting. In others, reduction of the dose caused subsidence of the side effects.

There was no effect on the liver function tests, nor on the haemogram. Serum and urinary lactic acid was estimated in nine cases. The level in the serum was raised in eight patients, the range being 30 to $40 \mathrm{mg} . / 100 \mathrm{ml}$. Lactic acid in 24 hours urine sample was raised in two subjects only, $312 \mathrm{mg}$. in one and $320 \mathrm{mg}$. in the other.

\section{Follow up and secondary failures}

The 49 patients who were satisfactorily controlled by DBI-TD alone were followed up for 10 months. The minimum period of follow up was four months. Details are given in Table 8.

During the period of observation (10 months) two patients escaped control and in one it was most probably due to non-adherence to strict dietetic regime. 


\section{Combination therapy}

Combination of DBI-TD with sulphonylureas or insulin was attempted in 13 patients. Eight of them had earlier treatment with DBI-TD alone, with poor response in four and primary failure in four. Of the remaining five, two were having insulin and three received sulphonylureas with poor response to chlorpropamide in two and secondary failure to tolbutamide in one.

Out of these 13, six received insulin plus DBI-TD. Two of them were already receiving insulin. Two were poor response cases to chlorpropamide and another two had poor response to DBI-TD alone. Satisfactory response was obtained in five including those who had poor response to DBI-TD. The average reduction in insulin requirement was $57 \%$. Of the seven remaining patients who received combination therapy consisting of DBI-TD and one of the sulphonylurea derivatives (chlorpropamide or tolbutamide), two responded satisfactorily and five failed. The two successful cases did not have any antidiabetic treatment previously and exhibited poor response to DBI-TD alone. Of the other five failure cases, one had secondary failure to tolbutamide and four had primary failure to DBI-TD. The previous treatment of these four cases included secondary failures to chlorpropamide in one, to tolbutamide in another and to both in the remaining two. It appeared therefore that successful result was considerably higher in fresh cases $(90 \%)$ compared to the previously treated $(67.2 \%)$.

\section{Discussion}

The pattern of diabetes mellitus in India is slightly different from its Western counterpart. While the maturity-onset type is common, the growth-onset juvenile type is rare indeed. The obese diabetics are also infrequent. Moreover a good proportion of the patients belong to the 20 - 40 age group but do not fall into any one of the above categories. It was therefore interesting to study the response of phenformin hydrochloride in these subjects. There have been only two Indian reports (Patel, Dhirwani and Deshpande, 1962; Ahuja, Rastogi and Dhar, 1964) on the use of the tablet form of the drug, tried on a small number of patients.

In the present study, comprising an unselected group of 90 patients, phenformin timed-disintegration capsules have been used with a satisfactory response in $74.3 \%$ of the cases; good control in $56.1 \%$ and fair control in $18.2 \%$. The result has been similar to that of Radding,, McHenry, Neely and Lumiss (1962) who obtained a $68 \%$ success rate in a series consisting of 68 patients, but inferior to that reported by Weller, Donesa and Morton (1962) of an $88 \%$ success rate amongst 100 patients.
During the period of follow-up which has now been extended up to 10 months only two patients have shown secondary failure. That secondary failure to phenformin is low has been emphasized by earlier workers too (Stowers, 1962).

Contrary to expectations, the result of the combination therapy with sulphonylurea has not been as good. This was because, unfortunately, five of the seven patients where the combination was attempted happened to be 'secondary failure' cases to one or the other sulphonylurea derivatives and four were primary failures with phenformin. We consider that the combination of sulphonylurea compounds and phenformin should not be attempted without a prior knowledge of the response of the patient to either drug, if disappointment is to be avoided. However in combination with insulin, the result was satisfactory and DBI-TD caused a $57 \%$ reduction of the insulin requirement. This confirms earlier observations (Stowers, 1960; Fabrykant and Ashe, 1961).

It has been reaffirmed recently that several factors tend to modify or influence successful $\longrightarrow$ therapy by oral compounds. These are: age ofo onset, body weight, previous insulin requirement and duration of diabetes. In the present study thesen factors and the result of DBI therapy on Indian diabetics have been evaluated.

The age of onset of the disease was found to modify the result considerably; the growth-onset type of the disease with age of onset below 20 yearso did not respond to the therapy, while in the maturity-? onset type with age of onset above 40 years a successful result was encountered in $91.8 \%$. No difference, therefore, is observed in the response of these two types from that reported in Western literature. However a sizeable proportion of the diabetics in the tropics do not conform to the above two classical groups; their age of onset lies between 20-40 years, many are underweight individuals who are relatively less sensitive to insulin but fairly ketoacidosis resistant, except under stressful circumstances. In the present series there were 26 patients who fell in this age group; many amongst them fitted the description of ' $J$ ' type of Hugh-Jones (1955). Recently Tripathy and Kar (1965) have drawn attention to the frequent incidence $(22.9 \%)$ of this type in Orissa, India. Therapy in such cases is not well defined, in spite of common prevalence of this type in our country. Only 15 of the 26 subjects responded to the DBI-TD therapy (57.6\%). The comparatively poor response in this age group compared to the maturity onset type is striking. This may be due to an inherent resistance to oral therapy of this type as well as to other factors. Detailed analysis showed that the poor response in this group was the result of age of onset rather than of other modifying factors. 
The duration of the disease was found to influence the result significantly, the failure rate being $38.3 \%$ with duration more than five years compared to only $9.5 \%$ in duration less than one year. However the effect of duration as already stated is primarily the influence of the age of onset. That response is unrelated to duration has also been found with other sulphonylurea compounds (Katz and Bissel, 1965). The success rates in the overweight and average-weight patients were $72.7 \%$ and $72 \%$ respectively in contrast to under-weight individuals in whom it was only $58.3 \%$. That body weight is a factor which can influence the result of oral therapy has been the impression of earlier workers as well (Waller and others, 1962; Sadow, 1963; Bernhard, 1965). However in the present study no statistical corroboration was observed in this matter.

We were also much impressed by the manner in which the successful patients invariably lost bodyweight. This property of phenformin is no doubt beneficial for obese diabetics but such cases are infrequently seen in India. Incidentally patients who gained weight during therapy displayed a poor response to the drug.

The relationship between pre-therapy fasting blood sugar and the type of control was also taken into consideration. It was found that with a higher blood sugar level (above $250 \mathrm{mg} . / 100 \mathrm{ml}$.) the success rate was considerably lower (only $53.8 \%$ ). Similarly, Radding and Zimmerman (1961) stated that DBI-TD was more effective when the fasting level was below $200 \mathrm{mg}$. $/ 100 \mathrm{ml}$. The dose and time required for control were also found to be related to the pre-therapy blood sugar level: $100 \mathrm{mg}$. a day for blood sugar below $200 \mathrm{mg}$. $/ 100 \mathrm{ml}$. and $150-200$ mg. a day for blood sugar above $200 \mathrm{mg}$. were generally required for a two to four weeks period for effective control.

It has been said of phenformin that it has widened the scope of oral therapy. Patients who failed to respond primarily or afterwards to the sulphonylurea derivatives could be successfully treated with phenformin before resorting to insulin (Stowers, 1960; Walker and Hannah, 1961; Stowers, 1962; Bloom, Newton and Bateman, 1964). This was only partially confirmed in the present study; about $45 \%$ of the patients failing to respond secondarily to one or the other of the sulphonylurea compounds responded satisfactorily to DBI-TD. On the other hand patients with secondary failure to both these drugs met with failure with phenformin also. It was also noticed that the patients who required for control large amounts of insulin (above 40 units) are less likely to respond successfully to phenformin. Odell, Donald, Donald and Williams (1958) had made similar observations.

With regard to the occurrence of gastrointestinal side effects, DBI-TD was found to be superior to the tablet form of the drug. It occurred in $18.8 \%$ of the subjects in this series whereas with the tablet form of the drug a much higher incidence $(35 \%)$ had been reported earlier (Walker and Hannah, 1961). We however feel that this incidence is still higher than reported earlier (Weller and others, 1962). In our cases the side effects occurred irrespective of the dose of the drug and in many cases these disappeared with persistence of the therapy.

\section{Summary}

The pattern of response to phenformin timeddisintegration capsules has been studied in 90 Indian diabetics. Used alone, a successful response has been obtained in $74.3 \%$. New cases responded better than those previously treated. The salvage rate amongst the sulphonylurea-failure cases was only $45 \%$. Combination with insulin led to considerable reduction in the dose of the latter. There were 9 primary and 2 secondary failures during the period of observation. In most cases control was achieved within 2 to 4 weeks with 2 to 4 capsules a day.

The type of diabetes seen in India is slightly different from that seen in the Western countries. A good proportion belongs to the age group 20 to 40 years and in them the success rate was only $57.6 \%$. However the drug was regarded as a welcome alternative in this group also before resorting to insulin. In the juvenile and the maturity-onset type there was no difference in response from that observed by the Western authors. Other factors which modified the response were the pre-therapy fasting blood sugar level and the status of nutrition. Most of the successful subjects lost weight during therapy and those who gained weight ended mostly in failure.

Side effects involving the gastrointestinal tract occurred in $18.8 \%$ and in some cases the severity warranted withdrawal of the therapy. Though the side-effects have been minimised by the timeddisintegration capsule, our patients were still more vulnerable than the Western counterpart.

We are indebted to the Director, Institute of Post Graduate Medical Education and Research and Surgeon Superintendent, S.S.K.M. Hospital, Calcutta, for allowing us to use hospital materials for this study and publish the same. We are very grateful to U.S. Vitamin \& Pharmaceutical Corporation (India) Ltd. for supplying a large quantity of Phenformin hydrochloride (DBI TD) capsules required for this trial.

\section{REFERENCES}

Ahuja, M. M. S., Rastogi, G. K., and Dhar, S. N. (1964): Phenformin (DBI) in the Treatment of Diabetes Mellitus, J. Assoc. Phycns India, 12, 709.

BeAser, S. B. (1960): Orally-given Combination of Drugs in Diabetes Mellitus Therapy, J. Amer. med. Ass., 174, 2137. 
Bernhard, H. (1965): Long Term Observation on Oral Hypoglycaemic Agents in Diabetes: The effect of Carbutamid and Tolbutamide, Diabetes, 14, 59.

Bloom, A., Newton, M. A., and Bateman, M. (1964): Assessment of Oral Therapy in Diabetes Mellitus, Postgrad. med. J., 40, 654.

CosnetT, J. E. (1959): Diabetes among Natal Indians, Brit. med. J., 1, 187.

DeZoYsA, V. P. (1951): Clinical Variations of the Diabetic Syndrome in a Tropical Country (Ceylon), Arch. intern. Med., 88, 812.

FABRYKANT, M., and ASHE, B. I. (1961): Use of Longacting Phenformin (DBI-TD) with Insulin and Insulin-dependant Diabetes, Metabolism, 10, 684.

Hugh-Jones, P. (1955): Diabetes in Jamaica, Lancet, ii, 891.

KeTZ, H. M., and Bissel, G. (1965): Blood Sugar Lowering Effects of Chlorpropamide and Tolbutamide. A Double Blind Co-operative Study, Diabetes, 14, 650.

Odell, W. D., Donald, G. T., Donald, F. S., and Williams, R. H. (1958): Phenethyl, Amyl and Isoamylbiguanide in the Treatment of Diabetes Mellitus, Arch. intern. Med., 102, 520.

Patel, J. C., Dhirwani, M. K., and Deshrande, N. (1962): Clinical Trials with D.B.I., J.J.J. Hosp. Grant med. Coll., 7, 1.
Radding, S. R., and Zimmerman, S. J. (1961): Phenethyldiguanide - Comparative Study of Tablets and TimedDisintegration Capsule, Metabolism, 10, 238.

Radding, S., McHenry, I. I., NeEly, W. B., and Lumiss JR., F. R. (1962): Phenethylbiguanide: Clinical Experiences with Timed-Disintegration Capsules in Stable Diabetes Mellitus, Metabolism, 2, 404.

SADow, H. S. (1963): A Fundamental Approach to Hypoglycaemic Therapy, Metabolism, 12, 333.

STOWERS, J. M. (1960): The Value of Phenformin in the Treatment of Unstable Diabetes, Proc. roy. Soc. Med., 53, 603.

STOWERS, J. M. (1962): Treatment of Diabetes with Oral Compound from "Disorders of Carbohydrate Metabolism" Ed. by Pyke, D. A., p. 118. London: Pitman Medical.

TRIPATHY, B. B., and KAR, B. C. (1965): Observation on Clinical Patterns of Diabetes Mellitus in India, Diabetes, 14, 404.

WALKER, R. S., and HANNAH, R. (1961): Experiences with Phenformin, Diabetes, 10, 275.

Weller, C., DonesA, A., and Linder Morton (1962): The Phenformin Timed-Disintegration Capsule (DBI TD) in the Management of Previously Treated Diabetic Patients, Metabolism, 11, 1134. 